\title{
COMO PENSAR A IDENTIDADE NACIONAL EM ZONAS DE FRONTEIRA? UMA ANÁLISE A PARTIR DE DOIS CONJUNTOS DE CIDADES-GÊMEAS BRASILEIRO-ARGENTINAS ${ }^{1}$
}

\author{
HOW TO THINK NATIONAL IDENTITY IN FRONTIER ZONES? AN \\ ANALYSIS FROM TWO SETS OF BRAZILIAN-ARGENTINE TWIN CITIES
}

\author{
COMMENT PENSER L'IDENTITÉ NATIONALE DANS LES \\ ZONES FRONTIÈRES? UNE ANALYSE DE DEUX ENSEMBLES \\ DE VILLES JUMEAUX BRESILIENNES-ARGENTINES
}

Maristela Ferrari - Universidade Estadual do Oeste do Paraná - Cândido Rondon - Paraná - Brasil
maristela7ferrari@gmail.com

\begin{abstract}
The border area is a geographic space that emerges from the territorial political demarcating the boundary between two national states; it lies at the confluence between two territories based on two national identities built within the opposition between "the and others". But, far from being the only geographic political space, marked by the national identity and territorial belonging, the border area is also social and cultural space. Therefore, also refers to the idea of connection between two territories. Thus, the border area can be thought of as a place that reflects not only the division and the identity/alterity, because if people have multiple identities, the same can be said of places. These places were impregnated with colors that can reveal themselves in the most diverse forms of links or contacts between two officially established identities, among which we produce exchanges not only material but also immaterial, like the cultural. The purpose of this article is to analyze the processes of construction of national identities in a segment of the frontier zone brazilian-argentina and border practices front national identities officially established, notably in the twin cities Dionísio Cerqueira (SC)/Barracão (PR)/Bernardo de Irigoyen (MNES) and Santo Antonio do Sudoeste (PR)/San Antonio (MNES). The work was divided into two parts: the first analyzes the processes of construction of national identity by national states; the second part analyzes how the border inhabitants perceive the national identity and it is appropriated.
\end{abstract}

Keywords: Border Area. National Identity. Twin Cities. Cross-Border Interactions.

\section{Resumo}

A zona de fronteira é um espaço que emerge da demarcação do limite político-territorial entre dois Estados nacionais; ela se encontra na confluência entre dois territórios fundados sobre duas identidades nacionais construídas dentro da oposição entre nós e os outros. Mas, longe de ser apenas um espaço político-geográfico, marcado pela identidade nacional e pertencimento territorial, a zona de fronteira é também espaço social e cultural. Portanto, remete igualmente à ideia de ligação entre dois territórios. Assim, a zona de fronteira pode ser pensada como um lugar que não reflete apenas a divisão e a identidade/alteridade, pois, se as pessoas têm identidades múltiplas, pode-se dizer o mesmo dos lugares. Esses lugares estariam impregnados de cores que podem revelar-se nas mais diversas formas de ligações ou contatos entre duas identidades oficialmente instituídas, entre as quais se produzem trocas não apenas materiais, mas igualmente imateriais, como as culturais. 0 propósito deste artigo é analisar os processos de construção das identidades nacionais num segmento da zona de fronteira brasileiro-argentina e as práticas fronteiriças frente as identidades nacionais oficialmente instituídas, notadamente nas cidades- gêmeas Dionísio Cerqueira (SC)/Barracão (PR)/Bernardo de Irigoyen (MNES) e Santo Antonio do Sudoeste (PR)/San Antonio (MNES). 0 artigo está dividido em duas 
seções. A primeira apresenta os processos de construção da identidade nacional pelos Estados nacionais. A segunda analisa como os fronteiriços percebem a identidade nacional e dela se apropriam. Por fim, tecemos algumas considerações das quais resulta a afirmativa de que não há como negar que os habitantes fronteiriços nascem sob uma identidade geográfica, uma identidade nacional que indica o território de pertencimento, sendo que os fronteiriços não a negam, mas, em muitos aspectos, a manipulam, principalmente para barganhar interesses particulares. A manipulação das identidades nacionais em zona de fronteira, normalmente, ocorre frente à busca de serviços públicos gratuitos e limitados, como os da saúde.

Palavras-chave: Zona de Fronteira. Identidade Nacional. Cidades-Gêmeas. Interações Transfronteiriças.

\section{Abstract}

The border area is a geographic space that emerges from the territorial political demarcating the boundary between two national states; it lies at the confluence between two territories based on two national identities built within the opposition between "the and others". But, far from being the only geographic political space, marked by the national identity and territorial belonging, the border area is also social and cultural space. Therefore, also refers to the idea of connection between two territories. Thus, the border area can be thought of as a place that reflects not only the division and the identity/alterity, because if people have multiple identities, the same can be said of places. These places were impregnated with colors that can reveal themselves in the most diverse forms of links or contacts between two officially established identities, among which we produce exchanges not only material but also immaterial, like the cultural. The purpose of this article is to analyze the processes of construction of national identities in a segment of the frontier zone brazilian-argentina and border practices front national identities officially established, notably in the twin cities Dionísio Cerqueira (SC) / Barracão (PR) / Bernardo de Irigoyen (MNES) and Santo Antonio do Sudoeste (PR) / San Antonio (MNES). The work was divided into two parts: the first analyzes the processes of construction of national identity by national states; the second part analyzes how the border inhabitants perceive the national identity and it is appropriated.

Keywords: Border Area. National Identity. Twin Cities. Cross-Border Interactions.

\section{Résumé}

La zone frontalière est un espace qui émerge de la démarcation de la frontière politique territoriale entre deux États nationaux; elle c'est à la confluence de deux territoires fondés sur deux identités nationales construites dans l'opposition entre "nous et les autres». Mais, loin d'être un simple espace politique géographique, marqué par l'identité nationale et l'appartenance territoriale, la zone frontalière est aussi un espace social et culturel. Par conséquent, il renvoie également à l'idée d'une connexion entre deux territoires. Ainsi, la zone frontalière peut être considérée comme un lieu qui ne reflète pas seulement la division et l'identité / l'altérité, car si les personnes ont plusieurs identités, on peut en dire autant des lieux. Ces lieux seraient imprégnés de couleurs pouvant se révéler sous les formes les plus diverses de relations ou de contacts entre deux identités officiellement établies, parmi lesquelles se produisent non seulement des échanges matériels mais également immatériels, tels que des échanges culturels. L'objectif de cet article est d'analyser les processus de construction des identités nationales dans un segment de la zone frontalière entre le Brésil et l'Argentine et les pratiques frontalières auxquelles sont confrontées les identités nationales officiellement établies, notamment dans les villes jumelées Dionísio Cerqueira (SC)/Barracão (PR)/Bernardo de Irigoyen (MNES) et Santo Antonio do Sudoeste (PR)/San Antonio (MNES). Le travail était divisé en deux parties: la première analyse les processus de construction de l'identité nationale par les États nationaux; la seconde analyse la manière dont les les sujets frontaliers perçoivent l'identité nationale et se l'approprient. À la fin, nous faisons quelques considérations qui donnent lieu à l'affirmation de quoi on ne peut nier que les habitants de la frontière naissent sous une identité géographique, une identité nationale qui indique le territoire d'appartenance, et les frontaliers ne le nient pas, mais, à bien des égards, ils le manipulent, surtout pour troquer des intérêts particulier. La manipulation des identités nationales dans les zones frontalières se produit généralement lorsque l'on recherche des services publics gratuits et limités, tels que les services de santé. Mots clés: Zone Frontière. Identité Nationale. Villes Jumelées. Interactions Transfrontalières. 
Introdução

Os limites políticos-territoriais são historicamente instituídos para definir a soberania de uma entidade política, cercar simbolicamente o território de competência de um Estado nacional, distinguir o interno do internacional, provocar a descontinuidade entre normas e códigos nacionais e criar identidades diferenciadas. É certo que nenhuma sociedade, seja econômica, política ou social, poderia organizar-se sem limites territoriais, pois as leis que organizam e regem um território nacional carecem de limites. Traçados sobre o terreno, os limites políticosterritoriais assumem carga simbólica pelos símbolos nacionais lá dispostos (marcos de fronteira, bandeiras e outros) e criam funções diversas (fiscais, de controle etc.), são elementos que participam do fechamento e da organização dos territórios nacionais (Guichonnet; Raffestin, 1974). O território nacional se torna então lugar de representação política soberana, do exercício incontestável do poder e de coesão identitária, em que as pessoas se identificam e se reconhecem pela caracterização entre nós e os outros. É dentro desse território que a identidade nacional vai sendo construída em oposição aos outros ou aquilo que lhe é externo aos seus limites políticos-territoriais. Mas, é ao lado desses limites políticosterritoriais, com senso eminentemente de divisão política e identitária, que emergem as zonas fronteiriças, espaços que costeiam o limite no qual coabitam interesses das populações tornadas limítrofes (Velasco-Graciet, 1998).

Contudo, se o limite político territorial provoca a descontinuidade, separando entidades políticas e populações, gerando discursos identitários e fazendo surgir duas paisagens culturais diferenciadas, a zona de fronteira reúne, é ponto de contato que canaliza relações, é um espaço em que a sua coerência é assegurada pelas interações entre os atores dos dois lados do limite internacional. Portanto, ao invés da ideia clássica de divisão entre dois grupos que se constrói na relação da identidade/alteridade, a zona de fronteira pode ser pensada como espaço que remete à ideia de ligação entre dois territórios nacionais. Um lugar que não reflete apenas a divisão e a identidade/alteridade, pois, se as pessoas têm identidades múltiplas, pode-se dizer o mesmo dos lugares. Esses lugares estariam impregnados de cores que podem revelar-se nas mais diversas formas de ligações ou contatos entre duas identidades oficialmente instituídas, entre as quais se 
produzem trocas culturais materiais e imateriais (Claval, 2007; Massey, 2000).

Ao abandonar o conceito clássico de território para refletir sobre identidade nacional em zona de fronteira, Augé (1992, p. 33) alerta que é preciso "[...] duvidar das identidades absolutas, tanto no plano coletivo quanto no plano individual”. Para este autor, “[...] os indivíduos, por mais simples que possamos imaginá-los, não são jamais capazes de se situar em relação à ordem total que assina seu lugar; eles não exprimem a totalidade senão sob certo ângulo" (Augé, 1992, p. 33). Desse modo, o propósito deste artigo é analisar como se constrói a identidade nacional num segmento da fronteira brasileiro-argentina e quais são as práticas dos fronteiriços frente a essas identidades nacionais. Que papel o limite internacional joga sobre os habitantes fronteiriços? As interações transfronteiriças materiais e imateriais são elementos que fortalecem a identidade/alteridade?

$\mathrm{O}$ artigo está dividido em duas seções. A primeira apresenta os processos de construção da identidade nacional pelos Estados nacionais num segmento da fronteira Brasil-Argentina. A segunda analisa como os fronteiriços percebem a identidade nacional e como dela se apropriam. Para analisar essas questões geográficas e culturais, recorremos a uma análise teórica e pesquisa de campo. Na pesquisa de campo procuramos nos aproximar da geografia histórica do lugar e, neste sentido, foi fundamental os depoimentos dos sujeitos fronteiriços, isto é, habitantes da zona de fronteira, notadamente daqueles das cidades gêmeas brasileiro-argentinas - Dionísio Cerqueira (SC)/Barracão (PR)/Bernardo de Irigoyen (MNES) e Santo Antônio do Sudoeste (PR)/San Antonio (MNES) -, situadas no conjunto do extremo-oeste de Santa Catarina, extremo sudoeste do Paraná e nordeste da Província de Misiones (Argentina).

Finalizamos o trabalho mostrando que as zonas fronteiriças não são apenas espaços portadores dos limites internacionais ou espaços de separação de duas identidades nacionais e que para compreendêlas é preciso ir além da visão dos sujeitos com identidades nacionais diferenciadas, neste caso, de simples brasileiros e argentinos: é preciso ir ao encontro dos sujeitos fronteiriços com múltiplas identidades. O estudo ainda revela que os fronteiriços se apropriam das identidades nacionais e com elas jogam de acordo com seus interesses individuais ou coletivos, ora em benefício próprio, ora em colaboração com os centros políticos de poder. 
Processos de construção da identidade nacional na zona fronteiriça brasileiroargentina (1903 a 1930)

A zona fronteiriça no conjunto do extremo-oeste de Santa Catarina, extremo sudoeste do Paraná e nordeste da Província de Misiones, emerge oficialmente da instituição do limite político-territorial entre o Brasil e a Argentina. Antes disso, tal espaço não poderia ser caracterizado como tal, pois era território de grupos indígenas, área que fazia parte do imaginado projeto para a criação da República Guaranítica (XVII e XVIII). Pode-se dizer que a linearidade desse segmento de fronteira é relativamente recente - data de 1895 - e, como todos os limites políticos-territoriais, esse também só tem materialidade corpórea na cartografia. No terreno ele se distingue pelo curso dos rios Peperi-Guaçu e Santo Antônio, entre os quais se encontra a linha seca que se estende por aproximadamente 22 quilômetros de terras compreendidas exatamente entre os dois conjuntos de cidades-gêmeas Dionísio Cerqueira/Barracão/Bernardo de Irigoyen e Santo Antônio do Sudoeste/San Antonio (ver Figuras 1 e 2).

Figura 1 - Esquema da zona de fronteira brasileiro-argentina e cidades-gêmeas

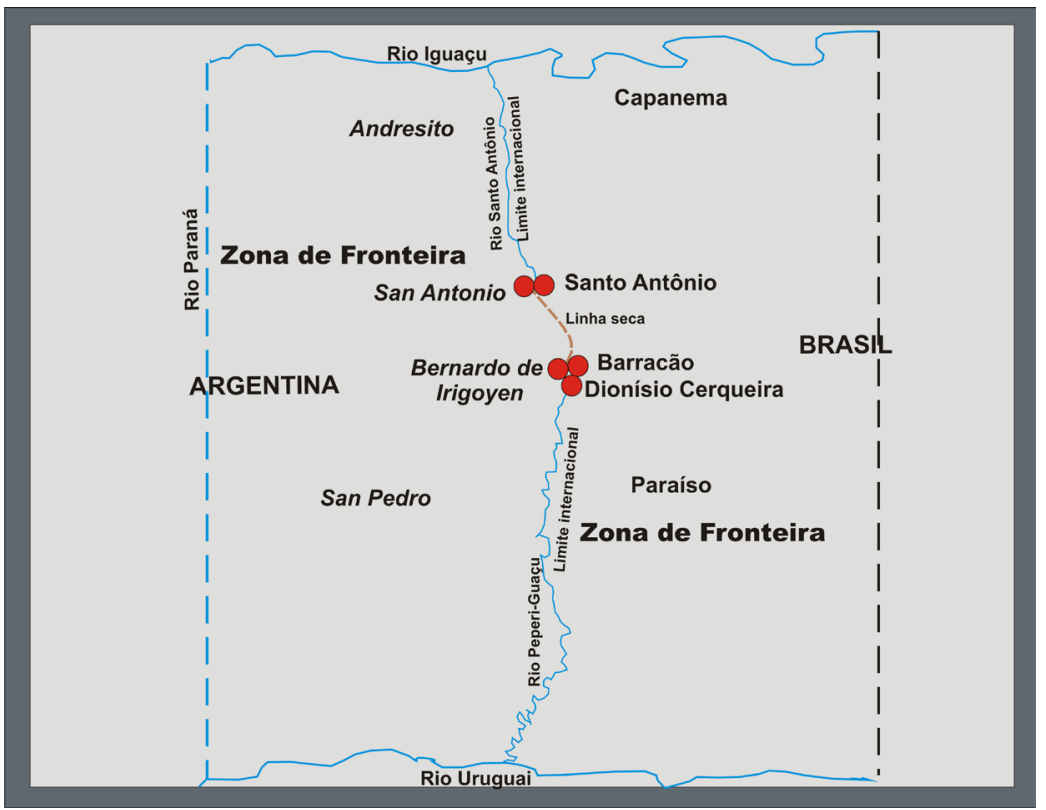

Fonte: Organizado pela autora (2011). 
Figura 2 - Localização zona de fronteira brasileiro-argentina

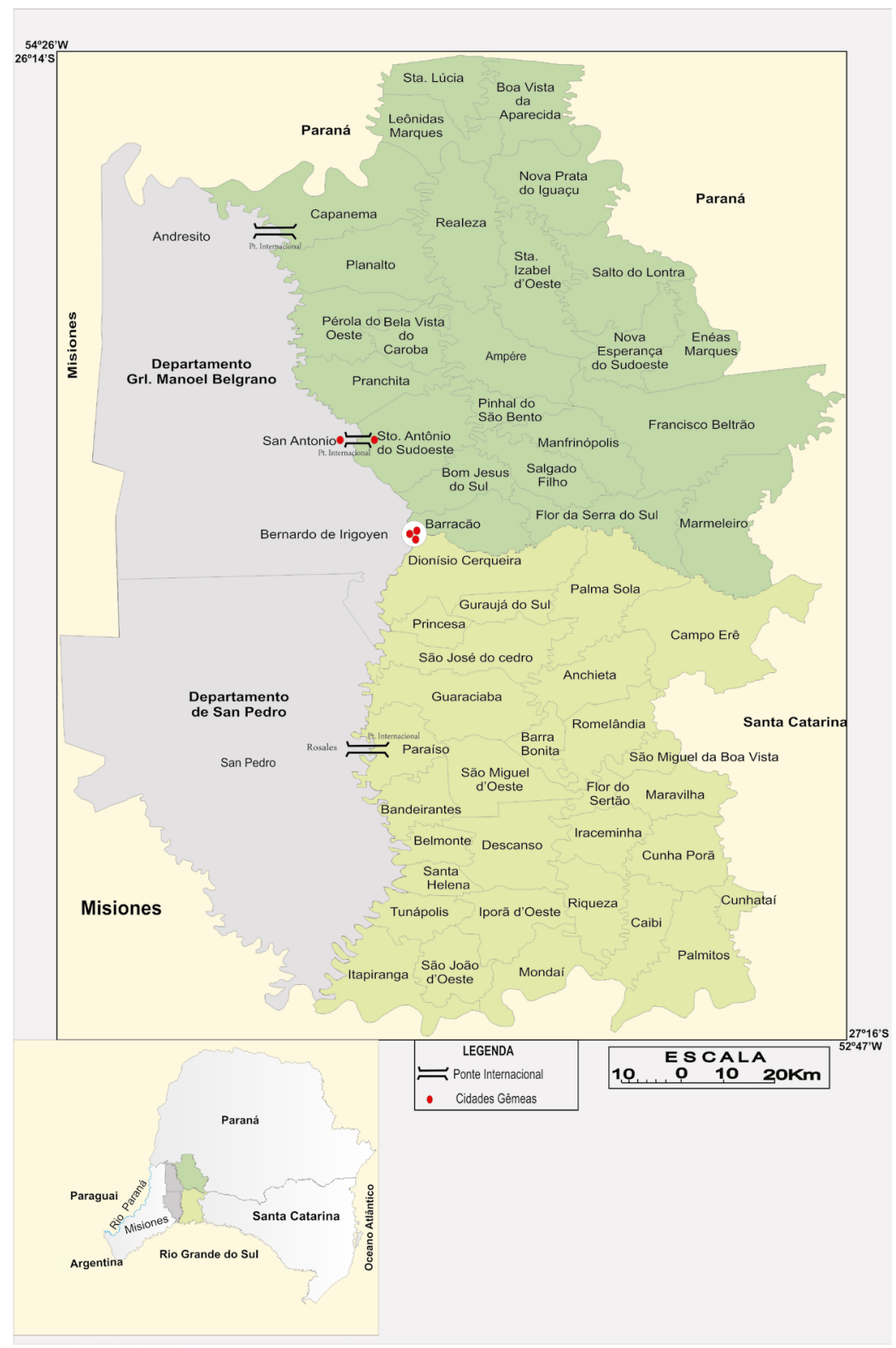

Fonte: Organizado pela autora (2011). 
Se estabelecermos um paralelo de referência entre os demais segmentos da fronteira Brasil-Argentina desde o oeste do Paraná até o sul do Rio Grande do Sul, constatar-se-á que a zona fronteiriça aqui analisada se diferencia totalmente das demais. Seu diferencial não está apenas na singularidade do limite internacional que permite fácil acesso entre os dois territórios vizinhos, mas igualmente porque nela se encontra a única passagem seca entre Brasil e Argentina, na qual o território brasileiro em continuidade com o argentino não apresenta rupturas físicas-naturais. Outra característica que distingue tal zona fronteiriça são as cidadesgêmeas conurbadas, inexistentes nos demais segmentos ao longo da fronteira Brasil-Argentina.

Embora a linha seca já figurasse em mapas desde 1895, data da definição do limite internacional entre Brasil e Argentina, no terreno ela seria demarcada somente em 1903, cujo traçado é representado por marcos de fronteira. Mas, antes mesmo de 1903, data da demarcação da linha fronteiriça no terreno, já se notava a presença de insignificantes aglomerados populacionais lá constituídos, em sua maioria, por descendentes de indígenas guaranis paraguaios e caboclos brasileiros que trabalhavam na extração da erva-mate silvestre em terras brasileiras. São exemplos de tais aglomerados: Barracón/Barracão (hoje Dionísio Cerqueira/ Barracão/Bernardo de Irigoyen) e San Antonio/Santo Antônio. Por exemplo: em 1903, Dionísio Cerqueira (SC), Barracão (PR) e Bernardo de Irigoyen (MNES) formavam um só aglomerado populacional chamado de Barracão/Barracón tanto por brasileiros quanto por argentinos, nome que se originou da construção de barracões para depósito de erva-mate. Prova disso é que em 1903, quando lá chegaram as Comissões demarcatórias de limites, formadas por brasileiros e argentinos, ao darem início à medição do terreno para demarcar a linha seca internacional, eles perceberam que o pequeno cemitério ali construído envolvia terras dos dois países, ou seja, parte dele estava em território brasileiro e parte dele em território argentino. Para evitar atritos com os locais, especialmente com as famílias dos mortos ali enterrados, a Comissão de Limites argentina cede extraoficialmente cerca de $200 \mathrm{~m}^{2}$ de terras em favor do Brasil. Mais tarde, tal campo-santo passou a chamar-se de cemitério internacional. Esse é um exemplo que nos leva a refletir sobre como os fronteiriços percebiam a identidade nacional no local, pois ao invés de nominarem tal campo-santo de cemitério brasileiro eles escolheram chamá-lo cemitério internacional. 
Aquela integração físico-social de Barracón/Barracão chama a atenção da Comissão de Limites brasileira e, ao término da demarcação da linha seca e da implantação de marcos de fronteira, em 1903, o General Dionísio Cerqueira eleva o povoado brasileiro à categoria de vila, uma forma de reforçar a identidade nacional e a soberania do Brasil naquela zona fronteiriça. A vila passou a chamar-se Dionísio Cerqueira em homenagem aos serviços por ele prestados. Em 1917, ao término do litígio territorial entre Paraná e Santa Catarina, a vila receberia novo limite político territorial, dando origem a outro aglomerado que em terras catarinenses passou a se chamar de Barracão, nome que permaneceu até 1938, quando passou a se denominar Dionísio Cerqueira, ficando o lado paranaense com o antigo nome de Barracão. O lado argentino permaneceu com o nome de Barracón até 1931, data em que passou a se chamar de Bernardo de Irigoyen (MNES), em homenagem ao advogado da Argentina que atuou na questão de limites entre Brasil e Argentina. Assim, de um único aglomerado, a divisão político-territorial entre países e Estados deu origem a três pequenos aglomerados que mais tarde evoluíram para cidades- gêmeas: Dionísio Cerqueira/Barracão/Bernardo de Irigoyen. Nelas, o grau de integração físico-social é hoje expresso pela própria malha urbana que se entrelaça sobre o limite internacional, formando verdadeira conurbação.

San Antonio/Santo Antônio também formavam um só aglomerado, mas este, ao contrário de Barracón/Barracão, não receberia tanta atenção política da comissão de limites brasileiro-argentina, pois já havia ali um elemento considerado fator divisório: o rio Santo Antônio, um "fio" de água corrente que passou a representar a linha internacional, por isso não houve preocupação na troca de nome daqueles aglomerados, apenas o lado brasileiro na década de 1950 acrescentaria o nome da região paranaense, ficando Santo Antônio do Sudoeste. Entretanto, diferentemente do olhar da comissão política de limites, os habitantes daquele aglomerado não viam o pequeno rio como fator de separação e nem de impedimento de quaisquer relações. Independentemente de suas nacionalidades, eles tinham a liberdade de transitar e de instalar suas residências onde melhor lhes conviesse. Aliás, logo após a passagem da comissão de limites brasileiroargentina, os habitantes de San Antonio/Santo Antônio do Sudoeste, sem prévia autorização do Brasil nem da Argentina, construíram uma ponte de madeira sobre o rio Santo Antônio. Segundo antigos moradores, essa 
teria sido a primeira ligação física por pontes sobre rios entre o Brasil e a Argentina. Portanto, assim como Dionísio Cerqueira/Barracão/Bernardo de Irigoyen, é difícil separar a evolução socioterritorial de San Antonio/Santo Antônio do Sudoeste, e mesmo havendo ali um "fio" de água corrente representando o limite internacional, as malhas urbanas se entrelaçam hoje sobre o limite, comprovando antigo ajuntamento físico-social. Tal união foi sendo estabelecida pelos fluxos e uma rede de relações sociais cotidianas, o que permitiu unir a territorialidade que fora dividida politicamente

Portanto, a partir de 1903, o limite político-territorial entre Brasil e Argentina dividiu os pequenos aglomerados lá constituídos. Além da troca de nomes dos pequenos aglomerados de Barracón/Barracão, para criar um sentimento de pertencimento sócio-territorial, as próprias relações entre os moradores seriam modificadas. Diante do limite internacional institucionalizado, as relações que antes se davam entre vizinhos passariam a ser com vizinhos que se tornaram estrangeiros. Dessa forma, o limite internacional passou a diferenciar o território brasileiro do argentino, criando uma descontinuidade entre normas e códigos nacionais e dando origem a espaços com identidades nacionais diferenciadas. Após a demarcação do limite internacional, a Argentina vai imediatamente instalar símbolos e equipamentos nacionais, como bandeiras, escolas, cartórios de registros, dentre outros, para nacionalizar aquele segmento fronteiriço argentino.

A ideologia política do Estado argentino foi a de fortalecer a identidade nacional dos fronteiriços que, em sua maioria, eram indígenas descendentes de guaranis e caboclos brasileiros. Naquele período, a Argentina acreditava firmemente que a identidade nacional passava pela educação. Para pôr em prática tal objetivo, o Estado nacional argentino institui escolas públicas nacionais, equipamentos de auxílio políticoideológico, pois é através das escolas que os Estados repassam suas ideologias. Além disso, é por meio das escolas que ocorre o ensino oficial da língua de um país e, na visão dos Estados nacionais, o ensino não é apenas um meio de comunicação, mas igualmente uma forma expressiva na formação de uma identidade nacional. Por isso, em 1909 foi instituída a primeira escola nacional em Barracón (hoje Bernardo de Irigoyen). Já em 1931, outra escola foi instalada em San Antonio. Além das escolas, foram implantados cartórios de registro civil. 
Já no segmento fronteiriço brasileiro, a questão da identidade nacional e pertencimento sócio-territorial seria preocupação do Estado nacional somente 26 anos mais tarde. Além do nome da vila Dionísio Cerqueira, os únicos indicativos da soberania brasileira eram os marcos fronteiriços, porém, diante de uma situação de isolamento físico-geográfico e da marginalização política econômico-social, aqueles marcos não teriam nenhum significado para os fronteiriços e logo ficaram encobertos pela vegetação. Não havia ali símbolos nacionais, escolas públicas e nem mesmo cartórios de registro civil que denotasse ser aquela região uma área de soberania brasileira.

Após a passagem da comissão de limites, os brasileiros lá residentes passaram a viver como segregados do Brasil, totalmente à margem do Estado nacional, principalmente em questões de políticas públicas, como educação e saúde. Aliás, até meados da década de 1950, no senso comum, a identidade brasileira tinha uma conotação pejorativa, sendo atribuída quase que exclusivamente aos caboclos. Os descendentes de imigrantes alemães, italianos, libaneses, dentre outros, lá residentes, mesmo nascidos em território brasileiro, não se identificavam como brasileiros, ao contrário, se identificavam muito mais com a identidade do país de migração de seus antepassados.

Como não havia cartórios de registro civil, as crianças nascidas em território brasileiro eram registradas na Argentina, e os meninos, quando completavam maioridade, mesmo morando em território brasileiro, eram convocados a servir o exército argentino. Além disso, como não havia escolas, as crianças brasileiras estudavam nas escolas do lado argentino. E, certamente, na visão do Estado nacional isso era uma desnacionalização, já que as crianças brasileiras aprendiam símbolos e datas importantes do país vizinho e desconheciam a história e os símbolos de seu próprio país, além de, é claro, aprenderem a ler e a escrever a língua do vizinho. Assim, as escolas argentinas, ao invés de fortalecerem a identidade nacional e criarem a alteridade, se tornaram espaços de interações culturais imateriais, já que as crianças brasileiras daquele segmento fronteiriço estudavam na Argentina. Anos mais tarde, tais interações seriam vistas pelo Estado nacional brasileiro como ilegais, e a zona fronteiriça passou a ser caracterizada como um espaço totalmente desnacionalizado do Brasil e de incerteza identitária. 
Somente a partir de 1929 o Estado nacional brasileiro começa a implantar escolas públicas e cartório de registro civil, dentre outros equipamentos, com o objetivo de criar um sentimento de pertencimento sócio-territorial e de identidade nacional. Mas, ao contrário do que se possa imaginar, nem a instituição do limite internacional e nem as ideologias políticas dos dois Estados nacionais foram fatores de fortalecimento identitário e separação daqueles aglomerados geminados. Os fronteiriços continuaram com seu sistema de relações, indiferentes ao limite territorial. Naquele segmento fronteiriço, a representação do limite internacional não tinha o mesmo significado político e ideológico dos Estados nacionais. A zona fronteiriça foi sendo transformada num lugar de reencontros, de trocas e transações de toda ordem, o que nos leva a pensar que, nesses lugares, as práticas e as representações quotidianas, podem opor-se a todo um ideário político nacional sobre os conceitos de limite, território e pertencimento sócio-territorial.

Pode-se inferir que a emergência da identidade nacional é obra política dos Estados nacionais e todo indivíduo, ao nascer, deve ter um documento indicando a qual território pertence, documento que, por consequência, indica ainda a identidade nacional. Neste sentido, o pertencimento territorial é, na concepção dos Estados nacionais, referência identitária (Vainer, 2008; Raffestin, 1993). Mas, é possível pensar que, a zona fronteiriça não reflete apenas duas identidades nacionais, pois, como já indicamos anteriormente, se as pessoas têm identidades múltiplas, o mesmo pode-se dizer dos lugares (Claval, 2007; Massey, 2000). O segmento fronteiriço aqui analisado evidencia que não existe apenas o brasileiro e o argentino, existem outros grupos que podem carregar múltiplas identidades, pois lá vivem descendentes de indígenas guaranis e kaingangues, caboclos, gaúchos, italianos, alemães, poloneses, russos, árabes, libaneses, suíços e outros, que interagem tanto pelas trocas materiais quanto pelas imateriais, podendo promover uma mescla, não significando a formação de uma única identidade e nem criando a alteridade entre identidades nacionais.

Práticas fronteiriças frente às identidades nacionais (1903 a 1929)

Apesar da divisão político territorial e das tentativas dos Estados nacionais em fortalecer as identidades nacionais, os habitantes fronteiriços 
fariam daqueles espaços verdadeiros espaços de integração. Seria o mesmo que pensar no processo de corte e costura: enquanto os Estados nacionais cortam os territórios com limites diferenciando o interno do internacional, os fronteiriços, com o fio das trocas materiais e imateriais, vão promovendo a costura dos territórios. No entanto, essa costura não se faz de forma imediata, ela se faz ao longo da história dos fronteiriços, uma história vivida e construída não apenas pelas alianças econômicocomerciais, mas com elos de solidariedade, afetividade, trocas sociais e culturais que são elos mais longos e duradouros porque fazem parte de uma trajetória de vida vivida na zona de fronteira.

Deste modo, em oposição às ideologias políticas nacionais, os fronteiriços foram construindo um conjunto socioterritorial unindo os dois lados do limite por interações transfronteiriças cotidianas não apenas materiais, mas igualmente imateriais, como as sociais e culturais que, de certa forma, contribuíram para a integração físico-social de pequenos aglomerados populacionais localizados na confluência do limite internacional e que mais tarde evoluíram para as cidades-gêmeas Dionísio Cerqueira/Barracão/Bernardo de Irigoyen e San Antonio/Santo Antônio do Sudoeste.

O que chama a atenção na geo-história daquelas cidades-gêmeas é que, embora as ideologias políticas entre Brasil e Argentina tentassem separá-las e fortalecer identidades nacionais, os fronteiriços foram formando uma rede de parentesco transfronteiriça tão estreita que até por volta de 1940 era praticamente impossível separar brasileiros de argentinos. Os contatos e práticas cotidianos entre os dois lados do limite resultavam frequentemente em casamento, o que foi promovendo a mescla que, aos olhos do poder, localizado no centro das escalas nacionais, seria verdadeira zona de incerteza identitária. Obviamente que as interações que lá iam sendo tecidas entre os fronteiriços contrariavam as políticas e ideologias do poder central das escalas nacionais e também todo um discurso sobre identidade nacional e pertencimento territorial.

A partir de 1929, com a implantação de equipamentos nacionais no lado brasileiro, dentre eles, escolas e cartórios de registro civil, poderíamos pensar que todas as crianças nascidas no lado brasileiro fossem registradas em território brasileiro. No entanto, a pesquisa de campo revelou que os registros de nascimento de crianças brasileiras na Argentina não se resumiam meramente à ausência daquele equipamento em Dionísio 
Cerqueira, Barracão e Santo Antônio do Sudoeste: havia também interesses particulares dos próprios habitantes da fronteira, que visavam a propriedades binacionais e também à instalação de estabelecimentos comerciais em ambos os lados do limite. Por essa razão, havia famílias brasileiras que optavam por registrar alguns filhos na Argentina e outros no Brasil; o contrário também é verdadeiro, pois quando surgiram cartórios de registro civil em lado brasileiro, muitas famílias argentinas também registravam alguns filhos em lado brasileiro. Como pensar a identidade nacional frente a essas práticas?

A título de exemplo, podemos citar aqui um peronista, residente em Barracão (PR). Filho de brasileiros, nasceu e foi registrado em Bernardo de Irigoyen em 1922. Isso aconteceu porque o seu pai, em 1917, migrou de Clevelândia (PR) para Bernardo de Irigoyen para trabalhar como guardalivros da empresa de erva-mate CREGI Sociedade Ltda., que explorava os ervais desde Palmas (PR) até Barracão (PR). Em 1924, após encerrar o trabalho naquela empresa argentina, seu pai retornou ao Brasil e foi morar no aglomerado de Barracão, onde o filho nascido na Argentina passaria sua infância e adolescência. Como ainda não tinha escola no lado brasileiro, a exemplo das demais crianças brasileiras, foi alfabetizado em Bernardo de Irigoyen.

Já aos 18 anos, mesmo residindo em território brasileiro, foi convocado a servir o Exército Argentino. No exército, em Buenos Aires, permaneceu por dois anos e foi lá que se tornou peronista convicto. Após deixar o exército, continuou por mais dois anos na Argentina e trabalhou no comércio. Posteriormente seu pai adoeceu e ele retornou ao Brasil, passando a residir em Barracão, onde iria trabalhar em diversas atividades do setor terciário. Trabalhou inclusive no setor de obras da prefeitura de Barracão, como uma espécie de contador e chefe encarregado do pagamento de 360 funcionários da ARBRA, uma grande madeireira de capital misto brasileiro-argentino na linha Tateto (hoje Flor da Serra). Foi lá que, em 1946, com um grupo de médicos fugitivos da Alemanha, aprendeu o oficio de "arrumador de ossos" e posteriormente se tornou o "ortopedista" dos fronteiriços de ambos os lados do limite internacional.

O curioso nesse relato é que esse fronteiriço dividiu sua vida entre os dois lados do limite internacional, inclusive a vida ativa de trabalho, pois trabalhou também em Bernardo de Irigoyen como uma espécie de "veterinário" dos criadores de animais e foi inclusive candidato a vereador 
naquela pequena cidade argentina. Sem detalhar aqui toda sua vida, rica em exemplos para compreender a questão da identidade nacional em zona de fronteira, ao final da entrevista de campo, questionamos: - O senhor se define como brasileiro ou argentino? Em meio a risos ele responde: - Eu sou um homem internacional! O exemplo desse fronteiriço não é único, ele representa e resume muitos outros exemplos e nos mostra que, independentemente do sentimento de identidade nacional, os sujeitos fronteiriços, devido as práticas cotidianas com o vizinho, são formados com múltiplos valores, o que fica particularmente evidente na resposta do entrevistado quando ele se define como um "homem internacional", pois ele não opta nem pela identidade argentina, nem pela identidade brasileira: ele opta pelas duas.

Por outro lado, sua resposta poderá ser interpretada como uma manipulação identitária para barganhar certos direitos em ambos os lados do limite, o que aos olhos do poder central das escalas nacionais pode ser visto como um ato ilegal. A identidade nacional é uma invenção dos Estados nacionais, desse modo, todo indivíduo ao nascer deve ser registrado, uma vez que o registro de nascimento torna-se um documento de pertencimento territorial, o que assegura direitos e deveres a um nacional. O território é, portanto, uma referência identitária (Vainer, 2008; Raffestin, 1993). Mas, pode-se pensar que, independentemente dos valores identitários nacionais que os fronteiriços internalizam ou carregam, eles muitas vezes forjam sua identidade nacional para de fato barganhar certos direitos em ambos os lados do limite internacional, notadamente direito aos serviços públicos gratuitos, como os médico-hospitalares, dentre outros. Mas é preciso levar em consideração as reais condições sociais e políticas das zonas fronteiriças e lembrar que, historicamente, os Estados nacionais com políticas centralizadoras estiveram de costas para os espaços fronteiriços, fato que ainda hoje se reflete nas zonas de fronteira do Brasil com os vizinhos, na qual a grande parte da população ainda está à margem de muitas políticas públicas dos Estados nacionais.

A partir de 1950, o limite político-territorial, naquele segmento fronteiriço brasileiro-argentino, passou a ser investido de maior controle político e fiscal. Desde então, a fiscalização se tornaria mais rigorosa sobre a circulação de pessoas e de mercadorias, mas isso não significou o rompimento de interações transfronteiriças materiais e imateriais. No entanto, as interações econômico-comerciais que antes 
não eram consideradas ilegais, passariam a ter conotação de contrabando descaminho, pois se realizavam fora do caminho da fiscalização, uma forma de driblar a fiscalização. Assim, quando alguém era preso fazendo descaminho, os fronteiriços, para libertar o preso, logo apelavam aos recursos históricos e culturais daquela zona fronteiriça argumentando um senso identitário comum. A esse respeito, é interessante observarmos o depoimento de um ex-prefeito de Santo Antônio do Sudoeste, que revela, em parte, como isso funcionava.

Aqui as cidades são gêmeas né, tem esse riozinho Santo Antônio, mas nunca dividiu nada! Aqui, no passado, a vida era tudo em comum, tudo em comum! Então, uma vez fui chamado pela Gendarmería de San Antonio para uma reunião, houve um problema né, prenderam lá um brasileiro, era um rapaz novo, mas prenderam sem motivo nenhum, né, daí mandaram me chamar e eu fui lá. $\mathrm{Na}$ época eu era prefeito. Aí, cheguei lá e perguntei: o que aconteceu? Eles: - ele foi preso porque tava levando contrabando²! Falaram, falaram e eu só ouvindo, né. Aí depois eu falei: - escuta, porque vocês prenderam esse rapaz? Só porque ele tava levando cinco quilos de farinha e dez pedaços de sabão a mais? Isso não é motivo para prender o rapaz! Nós aqui somos um corpo só, não temos divisão! Sabem o que significa o rio Santo Antônio pra nós? É uma artéria que liga os dois países, nós somos um corpo só! Aí um gendarme olhou pro outro e disse: - está livre, está livre, que se vá, que se vá! Foi assim que eu os fiz perceberem que estavam cometendo uma injustiça e o rapaz foi liberado sem maiores problemas! (Entrevista de Campo, 2008)

O depoimento acima é uma pequena amostra de como os fronteiriços se posicionam frente às normas territoriais nacionais: a favor ou contra elas. Por outro lado, revela também que, em oposição às normas territoriais de cada Estado nacional, os fronteiriços, ainda que estejam submetidos a uma identidade nacional, se reconhecem como pertencentes a uma única territorialidade construída pelas interações transfrontieiriças, notadamente por aquelas imateriais, como, os laços familiares e de parentescos, os laços de amizades e compadrio, dentre outros que os unem através de uma história construída no local, não por brasileiros e argentinos, mas pelos sujeitos fronteiriços. Assim, ao refletirmos sobre identidades nacionais num segmento fronteiriço brasileiro-argentino, poderíamos pensar imediatamente na existência de conflitos identitários e no fortalecimento da alteridade entre nós e os outros. Mas, quando 
nos aproximamos mais da zona fronteiriça e dos sujeitos ou habitantes fronteiriços, percebemos que eles não carregam apenas uma identidade nacional, eles são portadores de múltiplas identidades. As alianças matrimoniais geram a mescla e, em muitos momentos, eles se definem como sujeitos internacionais, não negam suas identidades nacionais, mas jogam com elas para justificar práticas informais comuns, mas condenadas como práticas transgressivas dos territórios nacionais.

\section{Considerações finais}

A zona fronteiriça não é somente espaço portador do limite internacional e de duas identidades nacionais, ela é, também, um meio geográfico particular, ou seja, um espaço que canaliza relações e é ponto de contato e de trocas materiais e imateriais. Na geografia cotidiana da zona fronteiriça, notadamente das cidades-gêmeas, ocorrem práticas sociais e culturais rotineiras entre amigos, parentes e familiares. As formas de ligações sociais que surgem nesse meio particular são inúmeras, desde aquelas geradas pelas práticas econômico-comerciais até aquelas geradas pela ausência de serviços públicos ou privados, como a saúde, por exemplo, ou aquelas geradas por valores imateriais, como solidariedade, afetividade, sentimentos, e que geram ligações e constantes mobilidades entre um lado e o outro do limite. Assim, podemos pensar que, em zona de fronteira, uma identidade nacional não se constrói e nem se fortalece numa relação de amizade, pois ela depende fundamentalmente de uma relação de alteridade entre nós e os outros. Melhor dizendo, ela depende de inimigos e não de amigos. Obviamente que a alteridade entre nós e os outros é claramente verificada nos centros de poder de cada Estado nacional.

As cidades-gêmeas têm formas particulares de organização que combinam duas lógicas espaciais - a local e a nacional - em que o sujeito fronteiriço, seja individual ou coletivo, trabalha com o legal e o ilegal. É o lugar no qual a geograficidade do habitante fronteiriço floresce. Nessa perspectiva, podemos ponderar que, as zonas de fronteira, notadamente aquelas formadas por cidades-gêmeas, são lugares que não são formados apenas pela racionalidade política territorial dos Estados nacionais, mas também pelos espaços carregados de sentido para aqueles que a habitam ou que a frequentam. 
Para finalizar, não há como negar que os habitantes fronteiriços nascem sob uma identidade geográfica, uma identidade nacional que indica o território de pertencimento, sendo que os fronteiriços não a negam, mas, em muitos aspectos, a manipulam, principalmente para barganhar interesses particulares. A manipulação das identidades nacionais em zona de fronteira, normalmente, ocorre frente à busca de serviços públicos gratuitos e limitados, como os da saúde. Na atualidade, os jogos identitários, ainda que em menor escala, seguem a mesma lógica do passado, principalmente quando se trata da busca de serviços públicos gratuitos, como os médico-hospitalares e odontológicos, e isso pode ser constatado não apenas nas cidades-gêmeas aqui analisadas, mas em todo o segmento fronteiriço do extremo-oeste de Santa Catarina, extremooeste do Paraná e Oeste do Paraná, regiões limítrofes com Argentina e Paraguai. No entanto, como indicado anteriormente, não se pode esquecer que, historicamente, os Estados nacionais estiveram de costas para os espaços fronteiriços. Fato que ainda hoje persiste em zonas de fronteira do Brasil com os vizinhos, nas quais parte significativa da população continua à margem de muitas políticas públicas dos Estados nacionais. Nesse sentido, em muitos aspectos verifica-se que a vulnerabilidade social e econômica leva habitantes fronteiriços a se contrapor as normas e leis territoriais e a manipular sua própria identidade para obter parcos benefícios, notadamente serviços de saúde e educação. De modo geral, pode-se ponderar que os Estados nacionais têm uma dívida histórica para com as populações fronteiriças, a de integrar plenamente tais populações nas políticas nacionais de saúde, educação e desenvolvimento social e econômico.

\section{Notas}

1 Este artigo é parte da minha tese de doutorado defendida em 2011, desenvolvida com o auxílio das bolsas CNPq (2007 e agosto de 2009 a 2010) e CAPES (Bolsa doutoradosanduíche no exterior de outubro de 2008 a julho de 2009).

2 Na década de 1950, Santo Antônio do Sudoeste e San Antonio não era ponto de fronteira habilitado para trocas comerciais e turismo, e, ainda que coubesse ao Brasil fiscalizar a quantidade de produtos e mercadorias de consumo corrente que entrava no país, a Gendarmería nacional argentina impunha a quantidade de produtos que podia sair do país, quem estivesse com produtos ou mercadorias acima do permitido era considerado ator do contrabando. 


\section{Referências}

AUGÉ, M. Non-Lieux: introduction à une anthropologie de la surmodernité. Paris: Éditions du Seuil, 1992.

CIATTONI, A. (Dir.). La géographie: pourquoi, comment? Objets et démarches de la géographie d'aujourd'hui. Paris: Éditions Yves Manhès ; Hatier, 2005.

CLAVAL, Paul. L'étude des frontières et la geographie politique. Cahiers de Geographie de Québec: Les frontières politiques, v. 18, n. 43, avr. 1974.

. A geografia cultural. 3. ed. Florianópolis : EDUFSC, 2007.

DULLIN, S. ; FORESTIER-PEYRAT, E. Les frontières mondialisées. Paris: Presses Universitaires de France: Paris, 2015

GUICHONNET, P. ; RAFFESTIN, C. Géographie des Frontières. Paris: Presses Universitaires de France, 1974.

MACHADO, L. O. Estado, territorialidade, redes: cidades gêmeas na zona de fronteira sul-americana. In: SILVEIRA, M. L. (Org.). Continente em chamas: globalização e territórios na América Latina. Rio de Janeiro: Civilização Brasileira, 2005.

. Limites, fronteiras, redes. In: STROHAECKER, T. M. et al. (Org.). Fronteiras e espaço global. Porto Alegre: AGB, 1998.

MASSEY, D. Um sentido global de lugar. In: ARANTES, A. A. (Org.). O espaço da diferença. Campinas: Papirus, 2000

RAFFESTIN, C. Por uma geografia do poder. São Paulo: Ática, 1993.

Éléments pour une Problématique des Régions Frontalières. L’Espace Géographique, n. 1, 1974.

SAHLINS, P. Frontières et identités nationales: La France et l'Esapgne dans les Pyrénées depuis le XVIIe siècle. Paris: Belin, 1996.

VAINER, M. Le pouvoir des territoires: essai sur l1interterritorialité. Paris: Economica, 2008.

VELASCO-GRACIET, H. La Frontière, Le territoire et Le Lieu: norme et transgression dans lês Pyrénées Occidentales. Thèse de Doctorat en Geographie. Université de Pau et Des Pays de L’Adour. Pau: UFR de Letres, 1998.

Maristela Ferrari - Licenciada em geografia, com mestrado e doutorado pela Universidade Federal de Santa Catarina. Atualmente, é professora na graduação e pós-graduação em Geografia na Universidade Estadual do Oeste do Paraná - campus Marechal Cândido Rondon. É membra do Grupo de Estudos sobre Fronteira, Território e Ambiente na mesma instituição. (iD) https://orcid.org/0000-0002-1010-7202

Recebido em 24 de abril de 2019 Aceito para publicação em 17 de junho de 2019 Publicado em XX de XXX de 2019 